\title{
Can L5 Be Trusted During Proximal Extension of Fusion? A Case Series and a Review of the Literature
}

\author{
DAVID CHENG,${ }^{1}$ MICHAEL HALL,${ }^{2}$ MS, BRYAN PENALOSA, MD,${ }^{3}$ OLUMIDE DANISA, ${ }^{3}$ MD, \\ WAYNE CHENG, MD \\ ${ }^{1}$ University of Southern California, California, Los Angeles, California, ${ }^{2}$ University of Riverside, Riverside, California, ${ }^{3}$ Loma Linda University, Loma Linda, \\ California, ${ }^{4}$ Veterans Health Administration, Loma Linda, California
}

\begin{abstract}
Background: Debate on whether to stop fusion at L5 or to extend fusion to S1 in a long spinal construct has been a controversial topic in spine surgery. Fewer data are available to support whether to include a prior solid fusion at L4L5 or to extend to S1 during a proximal extension of fusion to T10. The purpose of this review is to report and discuss 2 cases of L5 vertebra fracture after proximal extension of solid L4-L5 fusion to T10 and to provide a guideline to surgeons based on the available literature.

Methods: Case report and literature review.

Results: Literature review identified multiple publications with levels of evidence from level 2 to level 4 . Advanced L5-S1 degeneration with long-segment fusion to L5 is reported to be greater than $60 \%$ with a new rate of symptom development approaching 20\%-25\%. There is no prior literature specific to L5 fracture development after thoracic lumbar fusion with the lowest instrumented level at a fused L4-L5 segment. Reoperation rate is not consistently affected by the lowest instrumented vertebral level L5 versus sacrum/ilium.

Conclusions: Literature review is inconclusive as to the need to include the lumbosacral junction when performing a proximal extension of fusion from L5 to the thoracic spine, especially during a revision adult deformity surgery. Stress of the long lever arm of a long-segment thoracolumbar fusion above a prior solid L4-L5 fusion could cause the L5 vertebra to split in the coronal plane, resulting in vertebral body fracture even with a mildly degenerated disc at L5-S1 prior to surgery.
\end{abstract}

Level of Evidence: 4.

Lumbar Spine

Keywords: L5 vertebral body fracture, T10-L5 fusion, T10-S1 fusion, coronal plane fracture

\section{INTRODUCTION}

The decision regarding the level at which to terminate a long-segment fusion specific to L5 versus $\mathrm{S} 1$ has been debated for more than 3 decades. ${ }^{1,2}$ Even though the surgical indication to include the L5-S1 level is clear in the literature when there is preexisting pathology at $\mathrm{L} 5-\mathrm{S} 1,{ }^{1}$ prophylactic extension to the sacrum with a near normal anatomy at L5-S1 to decrease the chances of reoperation for distal junctional degeneration or failure has been controversial. ${ }^{3}$

Decision making for adult spinal deformity correction to choose the lowest instrumented vertebra with a preexisting L4-L5 solid fusion is even more perplexing when the L5-S1 level has near normal anatomy. There is clear evidence of more blood loss, longer surgical time/hospital stay, and higher pseudarthrosis rate with extension of fusion to the sacrum/ilium; ${ }^{4,5}$ on the other hand, stopping the fusion at L5 could result in a higher rate of distal junctional degeneration/failure, worsen sagittal balance, and potentially require more reoperations in the future. ${ }^{6}$

\section{CASE REPORTS}

\section{Patient 1}

Patient 1 is a 69 -year-old female with progressive lower back pain and bilateral lower extremities pain for 7 years. Lower back pain is 8/10; bilateral lower extremities pain is $5 / 10$. Pain is clearly worsened with standing and walking and partially relieved by leaning forward on a shopping cart.

Past Surgical History. History of L4-L5 posterior lumbar interbody fusion performed in 2004. She had minimal pain for 10 years after her initial surgery. 

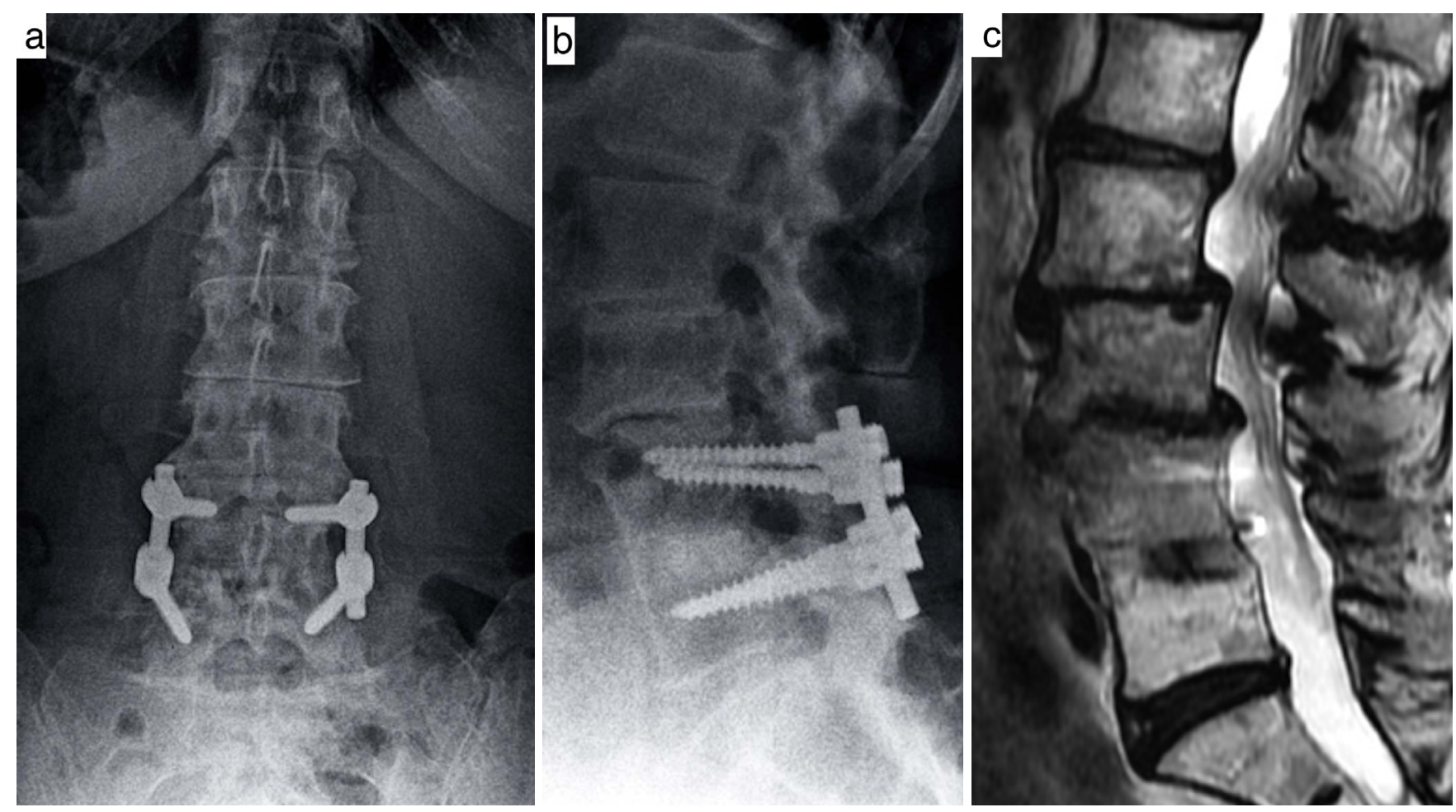

Figure 1. Anteroposterior and lateral x-ray (a, b). L4-L5 posterior lumbar interbody fusion performed in 2004. L2-L3, L3-L4 spondylolisthesis, L1-L2 retrolisthesis. Magnetic resonance imaging of the lumbar spine (c); sagittal T2 weighted image. Severe central stenosis L2-L4.

Physical Examination. A body mass index (BMI) of 23.3. No neurological deficit.

Imaging Studies. DEXA -1.8 of femoral neck. Scoliosis X-ray: L2-L3, L3-L4 spondylolisthesis, L1-L2 retrolisthesis (pelvic incidence $61^{\circ}$, pelvic tilt $22^{\circ}$, lumbar lordosis $54^{\circ}$, and sagittal vertical axis +3 $\mathrm{cm}$ ). Weiner classification: class $2^{7}$ (Figure 1a, b). Magnetic resonance imaging of the lumbar spine: severe central stenosis L2-L4 (Figure 1c).

Initial Procedure. The patient underwent a T10-L5 instrumented fusion with decompression L1-L4.

Complication. Three weeks after surgery, back and leg pain recurred. X-ray showed migration of the instrumentation and L5 fracture. Computed tomography (CT) evident for L5 coronal plane fracture with migration of instrumentation and kyphotic deformity (Figure 2a, b).

Final Procedure. Patient then underwent staged anterior interbody fusion at L5-S1 followed by stage 2 Ponte osteotomy at L5-S1; extension of fusion T10-S1 with iliac fixation. Patient had immediate resolution of symptoms.

\section{Patient 2}

Patient 2 is a 57 -year-old female presented with predominantly intractable back pain and a decompensated deformity. Lower back pain $10 / 10$ and bilateral lower extremities pain 10/10.

Past Surgical History. She had prior L4-L5 fusion performed in 1998 with transient pain relief less than 6 months and a spinal cord stimulator placement in 2007.

Physical Examination. A BMI of 16.3. Patient is very thin. Decompensated $15 \mathrm{~cm}$ to the right side. No neurological deficit.

Imaging Studies. DEXA -2.3 of femoral neck. Scoliosis x-ray: kyphoscoliosis with a Cobb angle of $52.7^{\circ}$ from L1 to L4, apex at L2 with positive sagittal vertical axis of $11 \mathrm{~cm}$ and lateral rotatory lithesis at L3-L4. Pelvic incidence is $47^{\circ}$ with pelvic tilt of $21^{\circ}$. Lumbar lordosis $13^{\circ}$ (Figure 3a, b). CT scan: solid fusion at L4-L5 (Figure 3c, d).

Initial Procedure. A stage 1, lateral interbody fusion performed at L1-L2, L2-L3, and L3-L4, with cement augmentation at L1-L4, followed 2 days later by a stage 2, posterior T10-L5 fusion with 

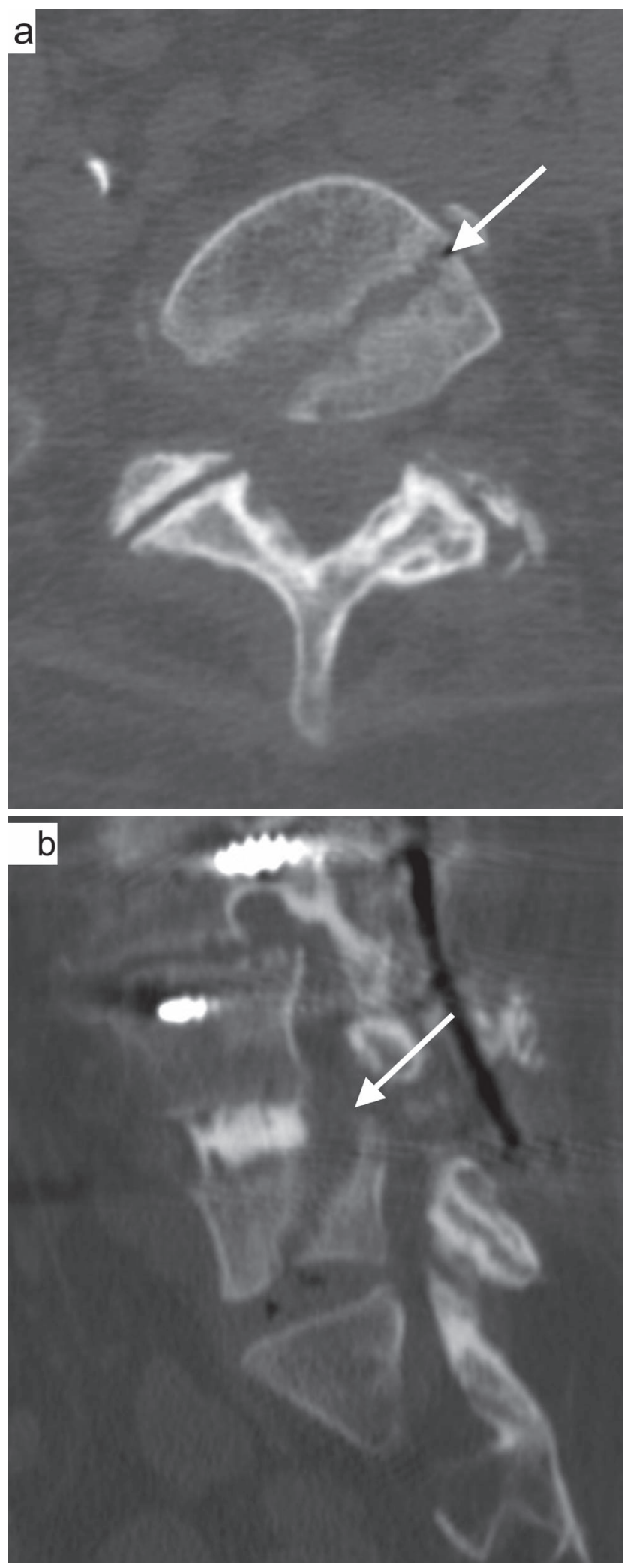

Figure 2. Computed tomography axial and sagittal views (a, b). Evident for L5 coronal plane fracture (white arrow).
T12-L4 Ponte osteotomy and cement augmentation from T9 to T11.

Complication. Two weeks postop, patient developed lower back pain and recurrence of kyphosis. An L5 vertebral body fracture was present with gross loosening of instrumentation.

Final Procedure. Patient underwent a second surgery with an anterior lumbar interbody fusion at L5-S1, followed by a stage 2 Ponte osteotomy at L5-S1; extension of fusion T10-S1 with iliac fixation. Patient had immediate resolution of symptoms (Figure 4a, b).

\section{RESULTS}

\section{Patient 1}

At 6-month follow-up, lower back pain improved from $8 / 10$ preoperation to $2 / 10$ postoperation. Bilateral lower extremities pain improved 5/10 preoperation to $0 / 10$ postoperation. Radiographically, the patient's lumbar lordosis improved from $54^{\circ}$ to $68^{\circ}$. Sagittal vertical axis increased from +3 to $+5 \mathrm{~cm}$.

\section{Patient 2}

At 6-month follow-up, lower back pain improved from $10 / 10$ preoperation to $4 / 10$ postoperation. Bilateral lower extremities pain improved from 10/ 10 preoperation to $1 / 10$ postoperation. Radiographically, the patient's lumbar lordosis improved from $13^{\circ}$ to $62^{\circ}$. Sagittal vertical axis decreased from +11 to $+5.5 \mathrm{~cm}$.

\section{DISCUSSION}

This report describes 2 cases of vertebral body fractures in the coronal plane at the level of L5 within 3 weeks after proximal extension of fused L4-L5 segment to T10. Both patients had confirmation of solid fusion of L4-L5 by CT prior to surgery. Both patients had osteopenia: -1.8 and -2.3. At the level of L5-S1, patient 1 had osteoarthritis/disc scoring of Weiner 2, and patient 2 had scoring of Weiner $1 .^{7}$

Coronal plane fractures are rarely described in the literature. Our institution reported coronal plane vertebral body fractures in 2011, but the fractures were due to transpsoas interbody fusion, ${ }^{8}$ not long instrumented posterior fusion. The amount of energy to create a fracture through a solidly fused 

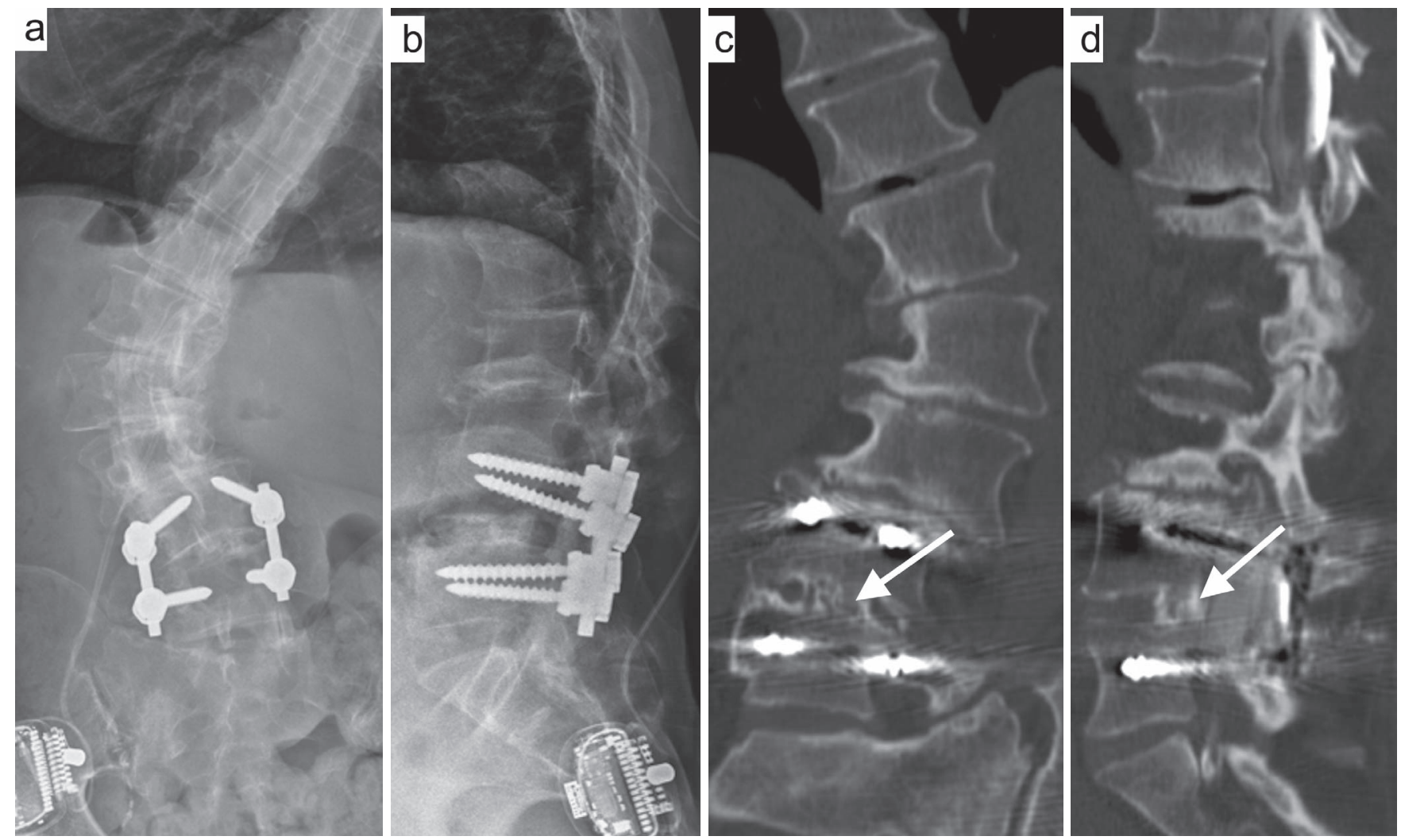

Figure 3. Anteroposterior and lateral $x$-ray of the lumbar spine (a, b). Prior L4-L5 fusion and spinal cord stimulator placement kyphoscoliosis with a Cobb angle of $52.7^{\circ}$ from $\mathrm{L} 1$ to $\mathrm{L} 4$, apex at $\mathrm{L} 2$ with positive sagittal vertical axis of $11 \mathrm{~cm}$ and lateral rotatory lithesis at L3-L4. Coronal and sagittal computed tomography scan (c, d) that demonstrates solid fusion (white arrow) at L4-L5.
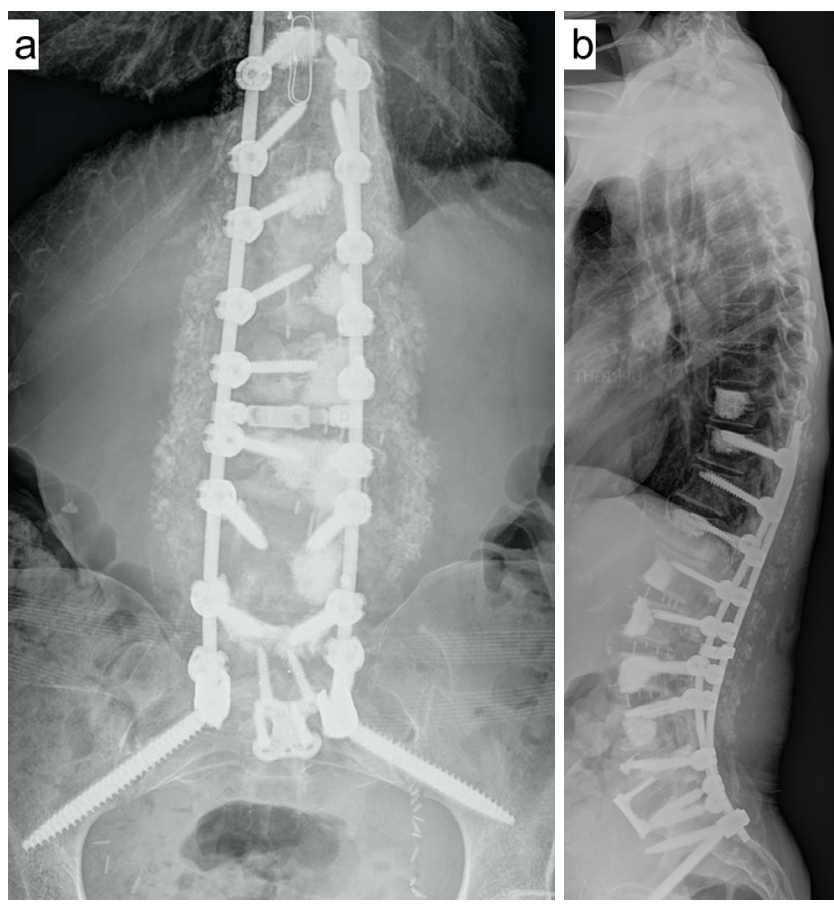

Figure 4. Anteroposterior and lateral scoliosis $x$-ray $(a, b)$. Anterior lumbar interbody fusion at L5-S1, followed by a stage 2 Ponte osteotomy at L5-S1; extension of fusion T10-S1 with iliac fixation. segment is tremendous, and it would be reasonable to assume that a similar type of force may go through the lowest instrumented level and cause distal junctional failure without fractures if L4-L5 is not solidly fused. ${ }^{9}$ This raises the following questions: Why does catastrophic distal junctional failure not happen more frequently in the long lever construct, and what are the incidence and risks factors for distal adjacent segment failure after long thoracolumbar fusion?

Rate of distal adjacent segment degeneration at the lumbosacral junction is well documented, ${ }^{10}$ but the risk factors for symptomatic degeneration are not entirely clear. Edwards et al ${ }^{11}$ in 2004 reported that $67 \%$ of L5 patients had radiographic evidence of advanced L5-S1 disc degeneration and inferior sagittal balance with a 5.2-year follow-up; $22 \%$ of those who developed advanced lumbosacral degeneration went on to have extension of fusion. Radiographic classification of L5-S1 was suggested as the key determining factor to stop at L5. Cho et $\mathrm{al}^{6}$ in 2009 also reported that $58 \%$ of the patients in the L5 group developed L5-S1 degeneration; $21 \%$ in the L5 group were symptomatic. It is interesting 
to note that the author in this study pointed out that the preoperative grade of disc degeneration did not correlate to the development of postoperative adjacent-level degeneration. The author also stated that sagittal imbalance is key determining factor to fuse to the sacrum.

Kasliwal et $\mathrm{al}^{12}$ provided a systematic review and reported rates of $45 \%-65 \%$ for developing radiographic distal adjacent segment pathology and $18 \%-20 \%$ for developing clinical distal adjacent segment pathology after long thoracolumbar fusion. Patients with preoperative sagittal imbalance greater than $5 \mathrm{~cm}$ were found to be almost 5 times more likely to develop clinical distal adjacent segment pathology. Other risk factors include higher postoperative fractional curve, younger patients with preoperative disc degeneration, longer fusion, and circumferential procedures. Another systematic review by Sardar et $\mathrm{al}^{13}$ in 2013 reported a revision surgery rate of $21 \%-24 \%$ in subjects who underwent spinal fusion to L5. This appears to be lower than the sacrum group with revision surgery rate of $19.0 \%-58.3 \%$.

Reoperation rates appear to be changing over the years comparing the group stop at L5 versus ilium. The overall prevalence of pseudarthrosis following long adult spinal deformity instrumentation and fusion to $\mathrm{S} 1$ is at least $24 \%{ }^{4}$ The improvement in sacropelvic fixation, including iliosacral screw and S2 alar iliac screw ${ }^{14,15}$ in addition to anterior column support, ${ }^{16}$ has significantly reduced the rate of pseudarthrosis and instrumentation failure with limited revision. ${ }^{17}$ Yasuda et $\mathrm{al}^{3}$ compared 2 group cohorts between iliac versus noniliac. Revision surgery was performed in $24 \%$ of noniliac group versus $7 \%$ of the iliac group.

L5-S1 disc/arthritis grading appears to be controversial as a key determining factor to go across lumbosacral junction in a long fusion. The latest report from Witiw et $\mathrm{al}^{5}$ in 2018 suggested that stop at L5 in the sitting of a normal or mildly degenerated L5-S1 disc space does not significantly change the risk of requiring a reoperation after a long-segment fusion for adult spinal deformity. In our case, the second patient has only grade 1 based on Weiner classification and still developed a catastrophic fracture. Future multifactorial statistical research should focus on identifying risk factors in addition to classification of L5-S1 disc degeneration by recruiting more cases from multiple institutions.

\section{CONCLUSIONS}

Stress of the long lever arm of a long-segment thoracolumbar fusion above a prior solid L4-L5 fusion could cause the L5 vertebra to split in the coronal plane, resulting in a vertebral body fracture even with a mildly degenerated disc at L5-S1 prior to surgery. Surgeons should counsel patients about the possible occurrence of L5 vertebral body fractures following extension fusion above L4-L5 and that additional surgery may be necessary to manage that complication. Shared decision making between surgeon and patient should take place on a case-by-case basis to arrive at a best judgment in each case.

\section{REFERENCES}

1. Bridwell KH, Edwards CC II, Lenke LG. The pros and cons to saving the L5-S1 motion segment in a long scoliosis fusion construct. Spine. 2003;28(20):S234-S242.

2. Polly DW Jr, Hamill CL, Bridwell KH. Debate: to fuse or not to fuse to the sacrum, the fate of the L5-S1 disc. Spine. 2006;31(suppl 19):S179-S184.

3. Yasuda T, Hasegawa T, Yamato Y, et al. lumbosacral junctional failures after long spinal fusion for adult spinal deformity - which vertebra is the preferred distal instrumented vertebra? Spine Deformity. 2016;4(5):378-384.

4. Eck KR, Bridwell KH, Ungacta FF, et al. Complications and results of long adult deformity fusions down to 14, 15, and the sacrum. Spine. 2001;26(9):E182-E192.

5. Witiw CD, Fessler RG, Nguyen S, et al. Re-operation after long-segment fusions for adult spinal deformity: the impact of extending the construct below the lumbar spine. Neurosurgery. 2018;82(2):211-219.

6. Cho KJ, Suk SI, Park SR, et al. Arthrodesis to L5 versus $\mathrm{S} 1$ in long instrumentation and fusion for degenerative lumbar scoliosis. Eur Spine J. 2009;18(4):531-537.

7. Weiner DK, Distell B, Studenski S, Martinez S, Lomasney L, Bongiorni D. Does radiographic osteoarthritis correlate with flexibility of the lumbar spine? J. Am Geriatr Soc. 1994;42(3):257263.

8. Brier-Jones JE, Palmer DK, Inceoglu S, Cheng WK. Vertebral body fractures after transpsoas interbody fusion procedures. Spine J. 2011;11(11):1068-1072.

9. Kwon BK, Elgafy H, Keynan O, et al. Progressive junctional kyphosis at the caudal end of lumbar instrumented fusion: etiology, predictors, and treatment. Spine. 2006;31(17):1943-1951.

10. Kuhns CA, Bridwell KH, Lenke LG, et al. Thoracolumbar deformity arthrodesis stopping at L5: fate of the L5-S1 disc, minimum 5-year follow-up. Spine. 2007;32(24):2771-2776.

11. Edwards CC II, Bridwell KH, Patel A, Rinella AS, Berra A, Lenke LG. Long adult deformity fusions to L5 and the sacrum. A matched cohort analysis. Spine. 2004;29(18):1996-2005.

12. Kasliwal MK, Shaffrey CI, Lenke LG, Dettori JR, Ely CG, Smith JS. Frequency, risk factors, and treatment of distal adjacent segment pathology after long thoracolumbar fusion: a systematic review. Spine. 2012;37(suppl 22):S165-S179.

13. Sardar ZM, Ouellet JA, Fischer DJ, Skelly AC Outcomes in adult scoliosis patients who undergo spinal fusion 
stopping at L5 compared with extension to the sacrum. Evid Based Spine Care J. 2013;4(2):96-104.

14. Kebaish KM. Sacropelvic fixation: techniques and complications. Spine. 2010;35(25):2245-2251.

15. Tsuchiya K, Bridwell KH, Kuklo TR, Lenke LG, Baldus C. Minimum 5-year analysis of L5-S1 fusion using sacropelvic fixation (bilateral $\mathrm{S} 1$ and iliac screws) for spinal deformity. Spine. 2006;31(3):303-308.

16. Weistroffer JK, Perra JH, Lonstein JE, et al. Complications in long fusions to the sacrum for adult scoliosis: minimum five-year analysis of fifty patients. Spine. 2008;33(13):1478-1483.

17. O'Shaughnessy BA, Lenke LG, Bridwell KH, et al. Should symptomatic iliac screws be electively removed in adult spinal deformity patients fused to the sacrum? Spine. 2012;37(13):1175-1181.

Disclosures and COI: Dr Danisa reports personal fees from Spineart and from Globus
Medical outside the submitted work. Dr Cheng reports fees from Medtronic and from DePuy/ Johnson \& Johnson outside the submitted work.

Corresponding Author: David Cheng, University of Southern California, University Park, Los Angeles, CA 90089. Phone: (909) 677-0522; Fax: (909) 906-1118; Email: davidche@usc.edu.

Published 30 June 2020

This manuscript is generously published free of charge by ISASS, the International Society for the Advancement of Spine Surgery. Copyright (c) 2020 ISASS. To see more or order reprints or permissions, see http://ijssurgery.com. 